\title{
Renin Response to Upright Posture in Varying Sodium Balance in Normal Young Japanese Men
}

\author{
Kenshi Kumamoto, M.D., Koshiro Fukiyama, M.D., \\ Yasuhiro Noda, M.D., Terukazu Kawasaki, M.D., \\ Shuichi Takishita, M.D., and Teruo Omae, M.D.
}

\section{SUMmary}

For the quantitative analysis of the effect of sodium balance on renin secretion, plasma renin activity (PRA) was measured in 9 healthy young males in the respective 3 - or 4 -day periods of sodium repletion, mild sodium restriction, moderate and severe sodium depletion. In the latter 2 periods, sodium balance was made negative by low salt diet and furosemide administration ( $120 \mathrm{mg} /$ day, p.o.) for 1 or 3 days. Blood samples for PRA determination were obtained at supine position (8:00 a.m.) and after 1-, 2-, and 4-hour's upright posture. PRA was also measured after furosemide stimulation ( $80 \mathrm{mg}$, p.o.) plus 2-hour's upright posture in the period of sodium repletion.

Change in the supine PRA was directly correlated with that in hematocrit $(\mathrm{r}=0.81)$ and inversely with that in body weight $(\mathrm{r}=-0.64)$. The PRA rose significantly from 1- to 2- and 4-hour's upright posture in the period of mild sodium restriction, whereas it reached the maximum level at 1-hour's upright posture and remained unchanged thereafter in either period of negative sodium balance. The upright PRA after furosemide stimulation in the period of sodium repletion was almost identical to 2- and 4-hour's upright PRA in the period of mild sodiom restriction, and less than 1-hour's upright PRA in either period of negative sodium balance.

These data suggest that 1-hour's upright posture is enough to evaluate PRA when sodium balance is negative.

\section{Additional Indexing Words :}

PRA in normal men Na blance Upright posture Furosemide stimulation

DLASMA renin activity (PRA) after 4-hour's upright posture with low sodium diet $(10 \mathrm{mEq})$ has frequently been used in hypertensive patients

From the Second Department of Internal Medicine, Faculty of Medicine, Kyushu University, Fukuoka, Japan.

Address for reprint: Koshiro Fukiyama, M.D., Second Department of Internal Medicine,

Faculty of Medicine, Kyushu University, Maidashi 3-1-1, Higashi-ku, Fukuoka 812, Japan.

Received for publication February 26, 1979.

Manuscript revised May 2, 1979. 
for diagnostic, therapeutic, and occasionally prognostic implications. ${ }^{1)-3}$ ) However, it has not yet been established whether orthostatism in low salt diet requires 4 hours to evaluate PRA in normal or hypertensive subjects. Since not so many patients are tolerable to keep upright so long, the shorter ambulation is desirable for patients. Furthermore, it seems not to be practical to supply the diet with only $10 \mathrm{mEq}$ of sodium, especially in Japan.

The present study was undertaken firstly to determine the effect of changes in sodium balance on the duration of upright posture required to get stable increase in PRA in normal subjects. Secondly, it was done to determine whether strict parallelism exists between changes in sodium balance and those in PRA in normal Japanese, whose daily intake of salt was much larger than that in Caucasians.4),51 Regular diet contains $260 \mathrm{mEq}$ or more of sodium per day in the Kyushu University Hospital. Racial difference in renin response is also well known.6),7) We limited our observations to healthy young males to exclude variable factors influencing PRA such as age and sex. ${ }^{8,9}$

In the present report, we described that $P R A$ reached the plateau level at the end of 1-hour's upright posture when sodium balance was made negative and that habitual intake of larger salt did not blunt the responsiveness of renin to changes in sodium balance.

\section{Materials and Methods}

Subjects were 9 male volunteers who were medical students ranging in age from 19 to 25 years with a mean of 22 . All were healthy, as determined by past history, routine physical examinations, urinalysis, ECG, chest X-ray, and routine blood chemistry. All denied the use of any drug and had blood pressure below $140 / 90 \mathrm{mmHg}$ on 2 visits at outpatient-clinic. Nature of the study was explained and informed consent was obtained from the subjects.

They were hospitalized for 17 days and studied in 4 dietary periods of 3 to 4 days each under the protocol as follows.

Period I (Low salt diet): The subjects were on a salt-free diet for 4 days, which still contained daily sodium of $34 \mathrm{mEq}$. To get a negative sodium balance, $120 \mathrm{mg}$ of furosemide was given orally in the morning of the first day.

Period II (High salt diet): In this period of 4 days, they were given a high salt diet containing $450 \mathrm{mEq}$ of daily sodium.

Period III (Control diet): Diet containing sodium of $194 \mathrm{mEq}$ was given for 4 days. Since regular diet contains about $260 \mathrm{mEq}$ of sodium per day in the Kyushu University Hospital, dietary sodium in this period is mildly restricted. This period was served as control period.

Period IV (Furosemide): Sodium depletion was produced by oral administration of $120 \mathrm{mg}$ of furosemide to the subjects on low salt diet containing 115 $\mathrm{mEq}$ of sodium for 3 days. One of the subjects dropped out in this period for personal reasons. Daily potassium intake was between 50 and $60 \mathrm{mEq}$ throughout the study. 
Body weight was checked every morning after voiding and the mean of the last 3 days in each period was compared with each other. Urine was collected for 24 hours and urinary excretions of sodium and potassium were measured every day except the 1st day of period III. At the 4th or 5th day of each period venous blood was obtained for determinations of PRA (supine PRA) and hematocrit at 8:00 a.m. after overnight fasting and recumbency. And then, the subjects were kept upright, followed by blood sampling at 1st, 2nd, and 4th hour in all periods except period II (High salt diet). Pulse rate was measured just before each blood sampling.

In period II, $80 \mathrm{mg}$ of furosemide was given orally immediately after blood sampling at 1-hour's upright posture and again blood was drawn 2 hours later in upright position. Fractional urine was also collected for determination of sodium.

Blood for PRA determination was drawn into an ice-cold vacutainer tube containing EDTA (Venoject ${ }^{\circledR}$, VT-050NA, Jintan Thermo Co, Tokyo). The plasma was immediately separated in a refrigerated centrifuge $\left(4^{\circ} \mathrm{C}\right)$ and stored frozen at $-20^{\circ} \mathrm{G}$ in a siliconized container until assay. PRA was determined by a radioimmunoassay, using CEA-IRE-SORIN kits based upon a variation of the assay system of Haber et al. ${ }^{10}$ Plasma was incubated at $\mathrm{pH}$ between 5.5 and 6.0 for 90 or $180 \mathrm{~min}$ using 1-to-1 dilution with enzymatic inhibitor 2-3 dimercaptopropanol and 8-hydroxyquinoline sulfate in buffer at $\mathrm{pH} 5$. Immunoassay of generated angiotensin I was carried out directly on plasma diluted $1: 10,1: 20,1: 50$, or 1: 100 if necessary. PRA was expressed as ng of angiotensin I generated per milliliter per hour. With each assay, control assay of a plasma pool was done. This pool had been separated into frozen aliquots, one of which was thawed with each assay. The coefficient of variation (C.V.) of within-assay was $5.3 \%$ in a sample producing a mean of $5.7 \mathrm{ng} / \mathrm{ml} / \mathrm{h}(\mathrm{n}=6)$. The reproducibility served as an internal control between assays. All samples for a given individual were assayed together.

Hematocrit was determined using a micromethod after centrifugation at 11000 rpm for exactly $5 \mathrm{~min}$ and a mean of 3 microtubes in each sample was used for analysis. Both serum and urinary electrolytes were measured with flamephotometer.

The results were expressed as mean \pm SE. Statistical analysis were done by Student's paired t-test, and differences were considered significant for $p<0.05$. Correlations were calculated using linear regression analysis.

\section{Results}

\section{Sodium balance, hematocrit, body weight and pulse rate:}

Cumulative sodium balance became positive in period II (High salt diet), while it did negative in cither period of I (Low salt diet) or IV (Furosemide). With the changes in sodium balance, hematocrit decreased in period II and vice versa in period $I$ and IV, whereas the body weight changed inversely with changes in hematocrit.

As shown in Fig. 1, furosemide administration induced marked natriuresis, averaging $283 \mathrm{mEq} /$ day, on the 1st day of period I. Thus the cumulative sodium balance was negative in this period. The urinary sodium excretion 


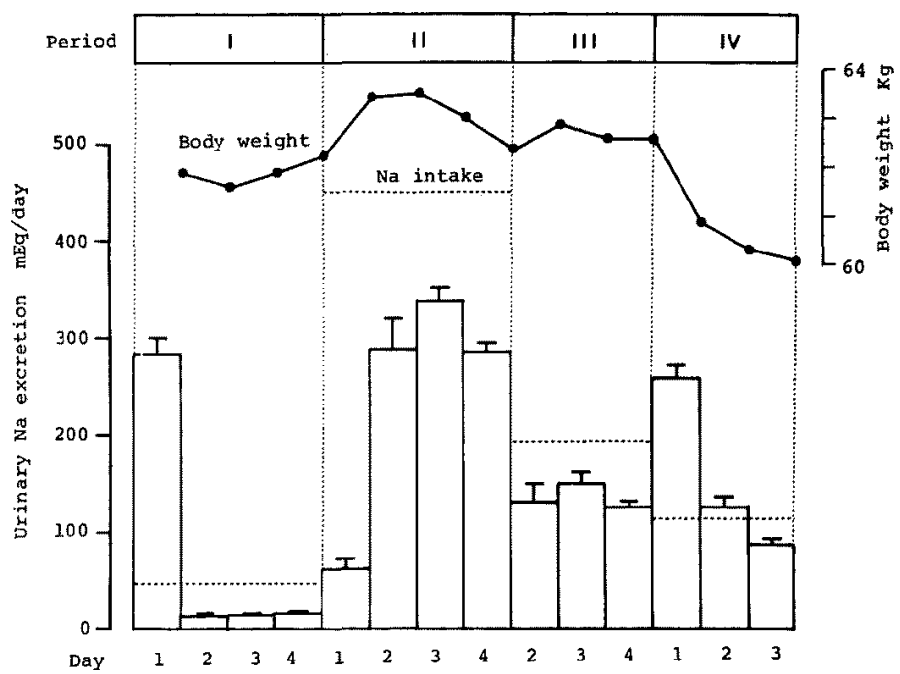

Fig. 1. Urinary excretion of sodium (Mean \pm SE) and body weight in each period of sodium balance. Period I, II, III, and IV denote periods of Low salt diet, High salt diet, Control diet, and Furosemide, respectively. See text.

in the last 3 days of the period I was $13 \pm 1,14 \pm 2$, and $14 \pm 3 \mathrm{mEq} /$ day, respectively. Only $62 \pm 10 \mathrm{mEq} /$ day of sodium was excreted in urine on the 1st day of period II, as it was influenced by negative sodium balance in period I. Through the 2 nd to 4 th day, the urinary sodium excretion was ranged between 288 and $338 \mathrm{mEq} /$ day. In period III (Control diet) daily sodium excretion in urine for the $2 \mathrm{nd}, 3 \mathrm{rd}$, and 4th day was $131 \pm 19,149 \pm 12$, and $125 \pm 6 \mathrm{mEq}$, respectively. Cumulative sodium balance was positive in both period of II and III. Urinary sodium excretion decreased progressively from the 1st to the 3rd day in period IV (Furosemide), which was 258 $\pm 13,125 \pm$ 11 , and $87 \pm 6 \mathrm{mEq} /$ day, respectively.

The mean values for hematocrit and the body weight in each period were summarized in Table I. The hematocrit in supine position for period I, II, III, and IV was $47.2 \pm 0.9,42.7 \pm 0.6,44.1 \pm 0.9$, and $48.6 \pm 0.7 \%$, respectively. It was low in period II $(\mathrm{p}<0.05)$, and higher in period I and IV $(\mathrm{p}<0.001)$ than that in period III (Control diet). It was also higher in period IV than period I $(p<0.05)$. The body weight was significantly reduced in period I and IV. The difference from period III was $+0.3 \mathrm{Kg}$ for period II, -0.8 for period I and -2.2 for period IV, respectively. The difference between period II and III was insignificant. The degree of weight loss was greater in period IV than that in period I ( $p<0.001)$, indicating, along with the result of hematocrit, much more sodium depletion in the former than the latter. Percent changes in the hematocrit from period III were 
Table I. Hematocrit (Ht) and Body Weight (BW) in Each Period of Sodium Balance

\begin{tabular}{cc|c|c|c|c}
\hline & $\begin{array}{c}\text { I } \\
\text { (Low salt diet) }\end{array}$ & $\begin{array}{c}\text { II } \\
\text { (High salt diet) }\end{array}$ & $\begin{array}{c}\text { III } \\
\text { (Control diet) }\end{array}$ & $\begin{array}{c}\text { IV } \\
\text { (Furosemide) }\end{array}$ \\
\hline \multirow{2}{*}{ Ht (\%) Mean } & $47.2^{* * * *}$ & $42.7^{*}$ & 44.1 & $48.6^{* * * *}$ \\
& SE & 0.9 & 0.6 & 0.9 & 0.7 \\
BW $(\mathrm{Kg})$ \$Mean & $61.9^{* *}$ & 63.0 & 62.7 & $60.5^{* * * *}$ \\
SE & 2.1 & 2.1 & 2.1 & 2.3
\end{tabular}

Significance of change was compared with period III. ${ }^{* * * *} \mathrm{p}<0.001,{ }^{*} \mathrm{p}<0.01,{ }^{*} \mathrm{p}<0.05$. $\$$ Body weight was a mean of the last 3 days in each period. Number of cases were 9 except in period IV $(n=8)$.

Table II. Effects of Changes in Sodium Balance and Posture on Pulse Rate

\begin{tabular}{|c|c|c|c|c|}
\hline \multirow{3}{*}{ Period } & \multicolumn{4}{|c|}{ Pulse rate (min) } \\
\hline & \multirow{2}{*}{ Supine } & \multicolumn{3}{|c|}{ Upright (h) } \\
\hline & & 1 & 2 & 4 \\
\hline I Low salt diet & $65 \pm 2$ & $87 \pm 5^{* * *}$ & $87 \pm 5$ & $89 \pm 4$ \\
\hline II High salt diet & $61 \pm 2$ & $80 \pm 4 * * * *$ & - & - \\
\hline III Control diet & $57 \pm 3$ & $87 \pm 5 * * * *$ & $87 \pm 4$ & $90 \pm 6$ \\
\hline IV Furosemide & $66 \pm 2$ & $113 \pm 8 * * * *$ & $108 \pm 9$ & $113 \pm 8$ \\
\hline Control v.s. Low salt diet & $* *$ & NS & NS & NS \\
\hline v.s. High salt diet & NS & $*$ & - & - \\
\hline v.s. Furosemide & $* * *$ & $* * * *$ & $* *$ & $* * * *$ \\
\hline Low salt diet v.s. Furosemide & NS & $* * * *$ & $* * *$ & $* * * *$ \\
\hline
\end{tabular}

The results were expressed as mean $\pm S E$. Significance of changes in pulse rate in each period was compared with the data just before.

${ }^{* * * *} \mathrm{p}<0.001, * * * \mathrm{p}<0,005,{ }^{* *} \mathrm{p}<0.01,{ }^{*} \mathrm{p}<0.05, \mathrm{NS}=$ not significant.

Number of cases were 9 except in period IV $(n=8)$.

inversely correlated with those in body weight $(r=-0.72, p<0.001)$.

The pulse rate in supine position was $57 \pm 3 / \mathrm{min}$ for period III, which was increased significantly after sodium depletion, $65 \pm 2$ for period $I$ and $66 \pm 2$ for period IV (Table II). On upright posture, the pulse rate increased significantly in all subjects regardless of sodium balance. The mean increase in pulse rate after 1 -h upright posture were $22 \pm 5 / \mathrm{min}, 19 \pm 3,30 \pm 5$, and $47 \pm 7$ for period I, II, III, and IV, respectively. The increase in pulse rate remained unchanged throughout upright posture in period I and III, whereas, in period IV, it showed a transient decrease at 2-h upright posture $(p<0.05$, vs 1-h upright posture). 
2. Plasma renin activity:

The mean value for PRA in each period of sodium balance and posture was summarized in Table III. The supine PRA in period III (Control diet) ranged from 1.0 to $5.4 \mathrm{ng} / \mathrm{ml} / \mathrm{h}$ with mean value of $3.1 \pm 0.5$. It was lowered with sodium repletion (period II), and increased with sodium depletion (period I and IV). The values were $1.3 \pm 0.3,10.1 \pm 2.0$, and 26.4 \pm 3.6 , respectively. The PRA in period IV was significantly higher than in period $I(p<0.005)$. The height of supine PRA was in the following order; period IV, I, III, and II.

In all the subjects, the PRA rose significantly by upright posture and remained elevated during erect position in all 4 periods. The mean increase in 1 -h upright position were $16.0 \pm 2.9 \mathrm{ng} / \mathrm{ml} / \mathrm{h}$ for period I, $3.8 \pm 1.1$ for period II, 6.1 \pm 1.4 for period III, and $31.0 \pm 4.9$ for period IV. The PRA in upright posture rose further through $1-\mathrm{h}$ to $2-\mathrm{h}$, reaching plateau level in period III (Control diet). It remained unchanged after 1-h upright posture in period I. In period IV, the PRA rose from $52.1 \pm 7.4 \mathrm{ng} / \mathrm{ml} / \mathrm{h}$ for $2-\mathrm{h}$ upright posture to $60.4 \pm 7.4$ for 4 -h upright posture, although the latter was

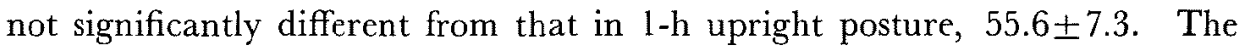
PRA was significantly higher in period IV than in period I in every erect position at 1-, 2-, and 4-h, and that in the latter was higher than in period III (Control diet).

The changes in supine PRA from period III were plotted against the

Table III. Effects of Changes in Sodium Balance and Posture on Plasma Renin Activity

\begin{tabular}{|c|c|c|c|c|}
\hline \multirow{3}{*}{ Period } & \multicolumn{4}{|c|}{ Plasma renin activity $(\mathrm{ng} / \mathrm{ml} / \mathrm{h})$} \\
\hline & \multirow{2}{*}{ Supine } & \multicolumn{3}{|c|}{ Upright (h) } \\
\hline & & 1 & 2 & 4 \\
\hline I Low salt dict & $10.1 \pm 2.0$ & $26.1 \pm 4.0 * * * *$ & $30.5 \pm 5.5$ & $27.9 \pm 4.6$ \\
\hline II High salt diet & $1.3 \pm 0.3$ & $5.1 \pm 1.1^{*}$ & - & - \\
\hline III Control diet & $3.1 \pm 0.5$ & $9.2 \pm 1.4 * * *$ & $10.8 \pm 1.6^{* * *}$ & $12.7 \pm 1.8$ \\
\hline IV Furosemide & $24.6 \pm 3.6$ & $55,6 \pm 7.3 * * * *$ & $52.1 \pm 7.4$ & $60.4 \pm 7.4^{*}$ \\
\hline Control v.s. Low salt diet & $* * *$ & $* * *$ & $* * *$ & $* *$ \\
\hline v.s. High salt diet & $* * *$ & $* * *$ & - & - \\
\hline v.s. Furosemide & $* * * *$ & $* * * *$ & $* * * *$ & $* * * *$ \\
\hline Low salt diet v.s. Furosemide & $* * *$ & $* * *$ & $*$ & $* * *$ \\
\hline
\end{tabular}

The results were expressed as mean $\pm \mathrm{SE}$. Significance of changes in plasma renin activity in each period was compared with the data just before.

$* * * * p<0.001, * * * \mathrm{p}<0.005, * \mathrm{p}<0.05$.

Number of cases were 9 except in period IV $(n=8)$. 

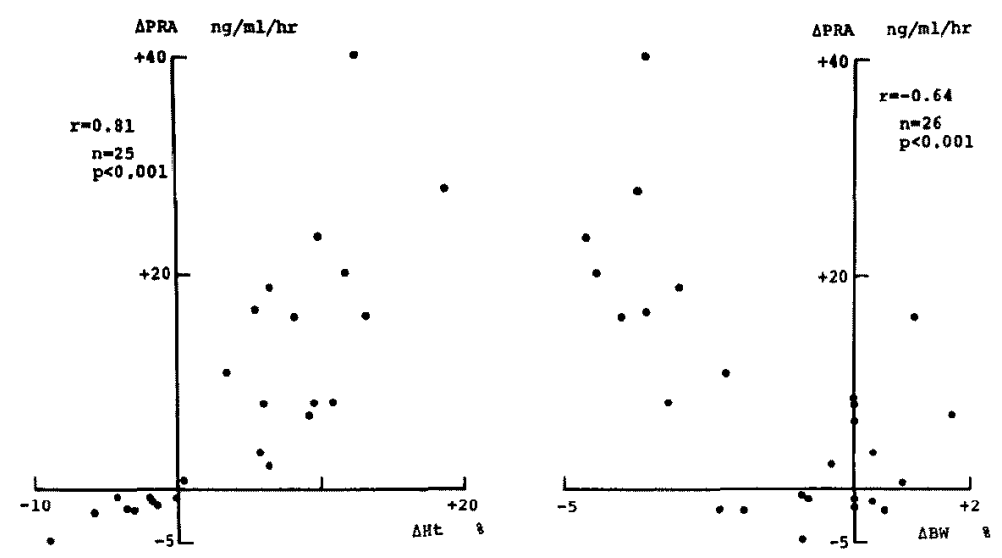

Fig. 2. Correlation between changes in plasma renin activity ( $\Delta \mathrm{PRA}$, $\mathrm{ng} / \mathrm{ml} / \mathrm{h}$ ) and $\%$ changes in hematocrit ( $\Delta \mathrm{Ht}$ ) (left side) or body weight $(\triangle \mathrm{BW})$ (right side) from the value in the control diet. Both $\triangle \mathrm{PRA}$ and $\mathrm{JHt}$ were changes in each parameter in supine position.

concurrent changes $(\%)$ in hematocrit or body weight. As shown in Fig. 2, the changes in supine PRA showed a close correlation with the changes in hematocrit $(\mathrm{r}=0.81, \mathrm{p}<0.001)$, and inverse correlation with the changes in body weight $(r=-0.64, p<0.001)$. The changes in supine PRA also correlated with concurrent changes in pulse rate $(r=0.40, p<0.05)$. Similarly, there was a direct correlation between the increase in PRA from supine to 1 -h upright posture and that in concurrent pulse rate $(r=0.52, p<0.005)$ (Fig. 3).

\section{Short-term renin stimulation:}

As described above, in period II, procedure of oral furosemide plus upright was done after obtaining blood at 1-h upright. The mean level at 1-h upright posture was $5.1 \pm 1.1 \mathrm{ng} / \mathrm{ml} / \mathrm{h}$, with a rise to $14.6 \pm 2.9$ after this test. The mean increase of $9.5 \pm 1.9$ was highly significant $(p<0.005)$. As shown in Fig. 4, the responsiveness of PRA to this test had relatively wide variations, ranged between 4.8 and $32.2 \mathrm{ng} / \mathrm{ml} / \mathrm{h}$. The urinary sodium $\mathrm{ex}-$ cretion after furosemide ingestion was ranged from 107 to $228 \mathrm{mEq}$ with a mean of $172 \pm 14 \mathrm{mEq}$ for 4 hours. The PRA after this test showed a close correlation with that at $1-\mathrm{h}$ upright posture $(\mathrm{r}=0.94, \mathrm{p}<0.001)$. There was no correlation between the response in PRA and the 4-h urinary excretion of sodium, nor was there any correlation of the PRA response to a given dose of furosemide per $\mathrm{Kg}$ of body weight.

The responsiveness of PRA to this test was compared with that observed in different sodium balance and posture in the present study (Fig. 5). The PRA after this test was significantly higher than the PRA at supine or 1-h 

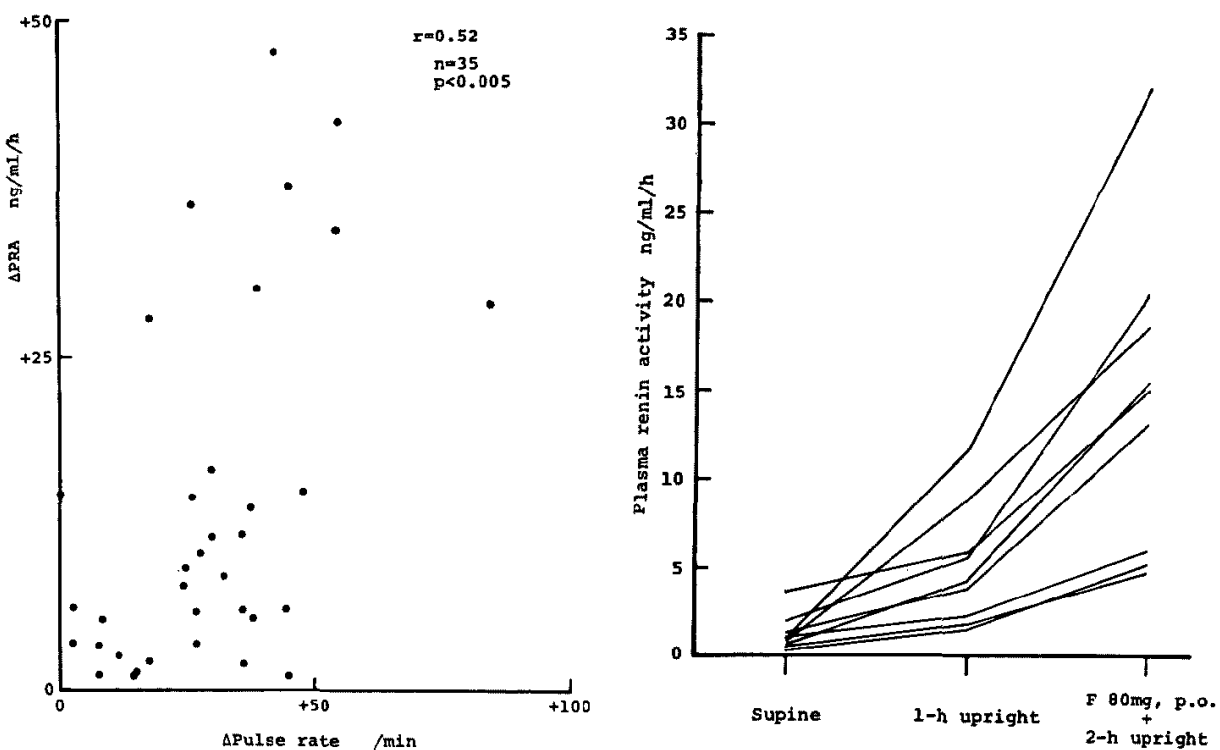

Fig. 3 (left). Correlation between changes in plasma renin activity $(\Delta \mathrm{PRA}, \mathrm{ng} / \mathrm{ml} / \mathrm{h}$ ) and those in pulse rate ( $\Delta$ pulse rate, $/ \mathrm{min}$ ) from supine to 1-h upright posture.

Fig. 4 (right). Effects of oral furosemide plus upright posture on plasma renin activity in period II (High salt diet).

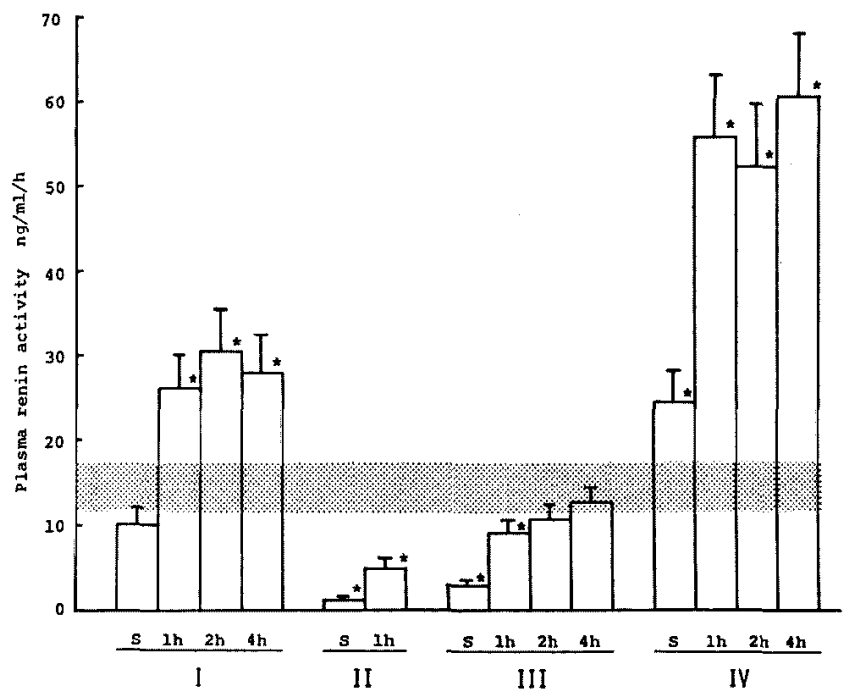

Fig. 5. Comparison of plasma renin activity after oral furosemide $(80 \mathrm{mg})$ plus upright posture $(2 \mathrm{~h})$ (shaded column) with that in each period of sodium balance and posture. Period I, II, III and IV denote periods of Low salt diet, High salt diet, Control diet, and Furosemide respectively. $S$ : supine position, $1-4 \mathrm{~h}$ : hours of upright posture. See text. 
upright posture in period III (Control diet), but not different from that at 2-h or 4-h upright posture. It was significantly lower than either PRA of 1-, 2-, and 4-h upright posture in period I (Low salt diet). As compared with the PRA in severe sodium depletion (period IV), the renin response to the test was even poorer than supine PRA in period IV. There was a close correlation between the PRA after this test and that of 1-h or 2-h upright posture in period III ( $\mathrm{r}=0.81, \mathrm{p}<0.01, \mathrm{r}=0.76, \mathrm{p}<0.02$, respectively). The former did not correlate significantly with the PRA of supine nor upright posture in period I or IV.

\section{Discussion}

Although the influence of sodium balance and posture on renin secretion have been well documented in normal or hypertensive subjects, it must be emphasized that few of the previous studies have described the maximal response of renin secretion to upright posture in various sodium balance. The present study showed that PRA rose from 1-h to 2-h upright posture and reached the plateau in period III (Control diet). The PRA after furosemide stimulation plus 2-h upright posture in the period of sodium repletion (period II) was not higher than that after 2 -h upright alone in period III and less than the 1-h upright PRA in either period of sodium depletion (period I and IV). These results suggest that, to obtain stable increase in PRA, orthostatism might require more than 2 hours when sodium intake is not sufficiently restricted. It was reported that PRA rose progressively until $120 \mathrm{~min}$ on upright posture in ad lib diet, ${ }^{11}$ ) whereas PRA reached peak level between 60 and $120 \mathrm{~min}$ of upright posture when sodium intake was $120 \mathrm{mEq} / \mathrm{day} .{ }^{12}$ ) The present results are compatible with those observations.

On the other hand, the PRA reached maximam level at 1-h upright posture and remained unchanged for another 1 or $3 \mathrm{~h}$ upright posture in moderate (period I) or severe (period IV) sodium depletion, in which cumulative sodium balance was negative. This suggests that orthostatism for an hour is enough as a stimulus for renin release when sodium intake is restricted or sodium balance is made negative.

Most investigators in United States have utilized $4 \mathrm{~h}$ of upright ambulation following 3 to 5 days of sodium-restricted diet $(10 \mathrm{mEq})$ as a standard stimulus to renin release. Negative sodium balance cannot be produced by sodium restriction alone in Japan because salt free diet still contains $35 \mathrm{mEq}$ of sodium, then we used furosemide in the present study. Since furoscmide has been suggested, besides its natriuretic effect, to stimulate renin secretion by direct action on macula densa cells ${ }^{13}$ and/or through baroreceptor mech- 
anism, ${ }^{131,14)}$ our data might not be compared with those obtained in the studies under sodium restriction alone. However, it might be necessary to determine whether or not orthostatism requires $4 \mathrm{~h}$ to evaluate PRA in normal or hypertensive subjects, because the time course of PRA for $4 \mathrm{~h}$ upright posture has not yet been established. A shorter ambulation is desirable for patients.

Yanomamo Indians of Brazil, who ate almost no-salt, had a strikingly high PRA. ${ }^{15}$ ) This is interpreted that augmented renin-angiotensin system is necessary to maintain sodium and fluid suitable to their circumstances. Since the amount of daily salt consumption is larger in Japanese than in Caucasians, ${ }^{41,5)}$ it might be supposed that renin response to changes in sodium balance was blunted in Japanese.

It was not true. The results clearly showed that changes in sodium balance were accompanjed by the corresponding changes in PRA both in supine and upright position (Table II). Furthermore, the changes in supine PRA show a significant positive correlation with those in hematocrit ( $\mathrm{r}=$ $0.81, \mathrm{p}<0.01)$, and a significant negative correlation with those in body weight $(r=-0.64, p<0.01$, Fig. 2). Increases in plasma and extracellular fluid volume were observed by salt loading and vice versa by salt restriction in normal subjects. ${ }^{16)-18}$ ) The correlation between PRA and hematocrit or body weight suggests an important role of renin-angiotensin system in maintenance of fluid and electrolytes balance in normal subjects.

In the present study, sodium depletion was accompanied by increase in pulse rate in supine position, and so was in erect position, which was the greatest in the most severe sodium depletion (period IV). This reflected the sympathetic stimulation caused by the decrease in circulating blood volume. ${ }^{19,20)}$ It is well documented that the activity of sympathetic nervous system has a regulatory effect on renin release in normal subjects. ${ }^{21,22}$ We reported previously that sodium depletion and upright posture caused an increase in serum dopamine- $\beta$-hydroxylase activity (DBH activity) and sodium loading suppressed it. ${ }^{231}$ Furthermore, a significant correlation was found between the changes in DBH activity and the PRA induced by manipulation of sodium balance. ${ }^{23)}$ Although the correlation was not very close in the present study, it was significant between the changes in supine PRA and those in pulse rate with sodium manipulations $(r=0.40)$, as well as between the changes in PRA from supine to 1-h upright position and those in pulse rate $(r=0.52)$. This seems to be a supportive evidence that activity of sympathetic nervous system contribute to regulation of renin release.

Several investigators reported that PRA in response to an oral furosemide plus 3-to 5-h of upright posture was quite comparable to that in low-salt diet 
plus upright posture. ${ }^{6), 24), 25)}$ In the present study, the potency of this procedure to stimulate renin release was compared with that in variable sodium balance and posture. Since usual salt intake in most of the Japanese is approximate to that in period II, the test was done in this period to examine its potency during daily life in normal subjects. The PRA was increased significantly by the procedure of oral furosemide plus 2-h upright posture in all 9 subjects. There was a close correlation between the PRAs before and after furosemide ingestion. The PRA in response to this test was similar to that of 2- or 4-h upright posture in period III (Control diet). It was greater than the supine PRA and less than the upright PRA in moderate sodium depletion (period I) and, even less than the supine PRA in severe sodium depletion (period IV). These results suggest that sodium balance affects largely the responsiveness of PRA to this short-term renin stimulation. A limiting factor of the increment of PRA in response to furosemide is probably basal PRA, which is dependent on sodium balance.

\section{Acknowledgements}

Authors are indebted to Miss J. Obata for her technical assistance. This study was partly supported by Japan Heart Foundation Research Grant for 1975.

\section{REFERENCES}

1. Conn JW, Cohen EL, Rovner DR: Suppression of plasma renin activity in primary aldosteronism. Distinguishing primary from secondary aldosteronism in hypertensive disease. JAMA 190: 213, 1964

2. Vaughan ED Jr, Laragh JH, Gavras I, Bühler FR, Gavras H, Brunner HR, Baer L: Volume factor in low and normal renin essential hypertension. Treatment with either spironolactone or chlorthalidone. Am J Cardiol 32: 523, 1973

3. Brunner HR, Laragh JH, Baer L, Newton MA, Goodwin FT, Krakoff LR, Bard RH, Bühler FR: Essential hypertension. Renin and aldosterone, heart attack and stroke, New Engl J Med 286: 441, 1972

4. Sasaki N: Relationship of salt intake to hypcrtension from an epidemiological viewpoint. Saishin-Igaku 26: 2270, 1971 (in Japanese)

5. Dahl LK: Possible role of salt intake in the development of essential hypertension. in Essential Hypertension, ed by KD Bock, PT Cottier, Springer-Verlag OHG, Berlin, p53, 1960

6. Channick BJ, Adlin EV, Marks AD: Suppressed plasma renin activity in hypertension. Arch Intern Med 123: 131, 1969

7. Kem DC, Kramer NJ, Gomez-Sanchez C, White M, Kaplan NM: The low renin state: definition and implications. J Clin Invest 52: 46a, 1973 (abstr)

8. Sambhi MP, Crane MG, Genest J: Essential hypertension. New concepts about mechanisms. Ann Intern Med 79: 411, 1973

9. Katz FH, Romfh P: Plasma aldosterone and renin activity during menstrual cycle. J Clin Endocrinol Metab 34: 819, 1972

10. Haber E, Koerner T, Page LB, Kliman B, Purnode A: Application of a radioimmunoassay 
for angiotensin I to the physiological measurement of plasma renin activity in normal human subjects. J Clin Endocrinol Metab 29: 1349, 1969

11. Sassard J, Vincent M, Annat G, Bizollon CA: A kinetic study of plasma renin and aldosterone during changes of posture in man. J Clin Endocrinol Metab 42: 20, 1976

12. Cohen EL, Conn JW, Rovner DR: Postural augmentation of plasma renin activity and aldosterone excretion in normal people. J Clin Invest 46: 418, 1967

13. Vandogen R: Intrarenal stimulation of renin secretion by furosemide in the isolated kidney of the rat. Brit J Pharmacol 60: 73, 1973

14. Corsini WA, Hook JB, Bailie MD: Control of renin secretion in the dog. Effects of furosemide on the vascular and macula densa receptors. Circulat Res 37: 464, 1975

15. Oliver WJ, Cohen EL, Neel JV: Blood pressure, sodium intake, and sodium related hormones in the Yanomamo Indians, a "no-salt" culture. Circulation 52: 146, 1975

16. Grant $H$, Reischman F: The effects of the ingestion of Jarge amounts of sodium chloride on the arterial and venous pressure of normal subjects. Am Heart J 32: 704, 1946

17. Brown WJ Jr, Brown FK, Krishan 1: Exchangeable sodium and blood volume in normotensive and hypertensive humans on high and low sodium intake. Circulation 43: 508, 1971

18. Kirkendall WM, Connor WE, Abbound F, Rastogi SP, Anderson TA, Fry M: The effects of dietary sodium chloride on blood pressure, body fluids, electrolytes, renal function, and serum lipids of normotensive man. J Lab Clin Med 87: 418, 1976

19. Neelsen I, Moller $\mathbf{I}$ : On the mechanism of renin stimulation: the effect of postural change, salt depletion and exercise. Acta Med Scand 186: 493, 1969

20. Molzahn M, Dissmann TA, Halin S, Lohmann FW, Oelkers W: Orthostatic changes of hemodynamics, renal function, plasma catecholamines and plasma renin concentration in normal and hypertensive man. Clin Sci 42: 409, 1972

21. Davis JO, Freeman RH: Mechanisms regulating renin release. Physiol Rev 56: 1, 1976

22. Davies $\mathrm{R}$, Slater JDH: Is the adrenergic control of renin release dominant in man? Lancet 2: 594,1976

23. Takishita S, Fukiyama K, Kumamoto K, Noda Y, Kawasaki T, Omae T: Plasma dopamine$\beta$-hydroxylase activity in normal young men. Its responsiveness to manipulation of sodium balance and upright posture. Jap Circulat J 41: 895, 1977

24. Wallach L, Nyarai I, Dawson KG: Stimulated renin: a screening test for hypertension. Ann Intern Med 82: 27, 1975

25. Drayer JIM, Kloppenborn PWC, Benraad TJ: Detection of low-renin hypertension; evaluation of out-patient renin-stimulating methods. Clin Sci Mol Med 48: 91, 1975 